http://jmscr.igmpublication.org/home/

ISSN (e)-2347-176x ISSN (p) 2455-0450

crossref DOI: https://dx.doi.org/10.18535/jmscr/v7i7.61

Journal Of Medical Science And Clinical Research

IGM Publication

An Official Publication of IGM Publication

\title{
A Comparative study between Ondansetron, Dexamethasone and Propofol forprevention of Intraoperative nausea vomiting in Patients undergoing cesarean section under spinal anesthesia
}

\author{
Authors \\ Dr Debjani Dutta M.B.B.S ${ }^{1}$, Dr Neetika Mishra M.D ${ }^{2^{*}}$, Dr Santanu Ghosh M.D ${ }^{3}$ \\ ${ }^{1}$ Post Graduate Trainee, Department of Anaesthesiology, North Bengal Medical College \\ ${ }^{2}$ Associate Professor, Department of Anaesthesiology, North Bengal Medical College \\ ${ }^{3}$ Assisstant Professor, Department of Anaesthesiology, North Bengal Medical College \\ "Corresponding Author
}

Dr Neetika Mishra M.D

Associate Professor, Department of Anaesthesiology, North Bengal Medical College

\begin{abstract}
Background: Control of intraoperative nausea vomiting during caesarean section under spinal anaesthesia is a challenge for every obstetric anaesthesiologist mostly because of its multiple etiology. In this study, the effects of IV Ondansetron (4 mg), Dexamethasone (8mg) and sub hypnotic infusion dose of Propofol were compared for prevention of intraoperative nausea and vomiting during caesarean delivery under spinal anaesthesia.

Materials and Methods: A comparative, double-blinded study was carried out on 90parturient $2^{\text {nd }}$ Gravida parturientby allocating them into three groups using computer-generated method. Group $O(n=$ 30) received intravenous (IV) Ondansetron $4 \mathrm{mg}$, Group $D(n=30)$ received (IV) Dexamethasone $8 \mathrm{mg}$ and Group $P(n=30)$ received Propofol $10 \mathrm{mg} I V$ bolus followed by an IV infusion of $1 \mathrm{mg} / \mathrm{kg} / \mathrm{hr}$ respectively after the delivery of baby and clamping the cord. Intraoperative emetic episodes were observed, and safety assessments were performed by an investigator, and propofol infusion was stopped at the end of surgery. Chi-square test and ANOVA were used for statistical analysis wherever appropriate and $P<0.05$ was considered significant.

Results: The maternal demographics and operative management were comparable among the three groups. The incidence of nausea, retching, and vomiting in the intraoperative, post-delivery period were: Group O: Group D: Group P Nausea $58.6 \%$ versus $10.3 \%$ and $20.6 \% \quad P=0.000$; Retching $44.8 \%$ versus $13.8 \%$ and $24.1 \% P=0.027$, Vomiting $41.3 \%, 13.7 \%$, versus $17.4 \% P=0.028$. No clinically significant adverse events were observed among the groups.

Discussion: The IV dexamethasone $8 \mathrm{mg}$ and IV Propofol $10 \mathrm{mg}$ bolus followed by infusion of propofol 1 $\mathrm{mg} / \mathrm{kg} / \mathrm{h}$ is better than IV Ondansetron $4 \mathrm{mg}$ for reduction of the incidence of nausea, retching, and vomiting in the caesarean section under spinal anesthesia.

Keywords: Antiemetic, caesarean delivery, ondansetron, dexamethasone, propofol, spinal anesthesia.
\end{abstract}

\section{Introduction}

Controlling intraoperative nausea vomiting during caesarean section under spinal anaesthesia is challenging for every obstetric anaesthesiologist. It is distressing for the mother and at the same time interferes with the surgical procedure. 
Multiple etiology has been suggested including hypotension associated with spinal block, vagal over-activity, uterine manipulation and gut handling, use of systemic opioids and uterotonic drugs. Regional anesthesia has been shown to be effective, safe, and the anesthetic of choice for elective and emergency caesarean sections. The incidence of nausea and vomiting during and immediately after caesarean delivery with spinal anesthesia is common ${ }^{(2,3)}$. Despite major advances in spinal, epidural, and combined spinal-epidural anesthesia techniques, the incidence of intraoperative nausea and vomiting (IONV) is more than $66 \% \%^{(1,2)}$.

Nausea is defined as a subjective unpleasant sensation associated with awareness and urges to vomit.Retching is defined as laboured spasmodic rhythmic contraction of respiratory muscles including diaphragm, chest wall, and abdominal muscles without expulsion of the gastric content. Vomiting is defined as forceful expulsion of the gastric content and is brought about by powerful sustained contraction of the abdominal muscles, descent of diaphragm and opening of the gastric cardia $^{(4)}$.

Ondansetron is a selective 5-HT3 inhibitor, and is devoid of dopamine, histamine, cholinergic, or adrenergic receptor activity. Abdominal surgery and its associated physical disruption and manipulation of abdominal viscera may cause the release of humoral substances including 5-HT, which stimulates 5-HT receptors peripherally on vagal nerve terminals and centrally in the chemoreceptor trigger zone of the area postrema, starting emetic reflexes especially in awake patients. Ondansetron $4 \mathrm{mg}$, given to parturient undergoing caesarean delivery under regional anesthesia showed decrease incidence and severity (5)

Propofol has been used at doses of $0.5-1.0$ $\mathrm{mg} / \mathrm{kg} / \mathrm{h}$ for the prevention and treatment of chemotherapy-induced emesis ${ }^{(3,6)}$ and to treat postoperative nausea and vomiting (PONV) without any side effects ${ }^{(7,8)}$. Propofol $1.0 \mathrm{mg} / \mathrm{kg} / \mathrm{h}$ has been found to be the minimum effective sub-hypnotic dose for reducing IONV during caesareansection $^{(9)}$.

Dexamethasone a potent corticosteroid has been shown to decrease nausea and vomiting associated with surgical stimulus. A meta-analysis of patient undergoing thyroid surgery has shown that dexamethasone in dose range of $8-10 \mathrm{mg}$ has shown to have greatest effect in reducing PONV $^{(10)}$.

In an attempt to search for the most effective antiemetic, in this study, we have compared intravenous (IV) the effects of IV Ondansetron (4 $\mathrm{mg}$ ), Dexamethasone (8mg) and sub hypnotic infusion dose of Propofol for prevention of intraoperative nausea and vomiting during caesarean delivery under spinal anaesthesia.

\section{Aims and Objectives}

The study was aimed for comparing the efficacy of Ondansetron, Dexamethasone and Propofol for prevention of intraoperative nausea and vomiting in parturient undergoing caesarean delivery under spinal anaesthesia.

\section{Materials and Methods}

After obtaining approval of the institutional ethics committee and informed consent from the patients concerned, a comparative, double-blinded study was conducted on parturient who were $2^{\text {nd }}$ Gravida with American Society of Anesthesiologists (ASA) physical Status I or II aged between 18 and 40 years undergoing caesareansection under spinal anesthesia during a period November 1, 2018 to May 31, 2019.

Exclusion criteria includes patients with allergy or hypersensitivity to Ondansetron, Dexamethasone and Propofol; history of nausea or vomiting within $24 \mathrm{~h}$ before CaesareanDelivery; history of gastrointestinal or psychiatric disease; morbid obesity;asthma, diabetes mellitus, cardiac disease, coagulopathy, neuropathy, renal or liver diseases, local infection at the site of spinal needle entry or septicemia,fetal prematurity and consumption of drugs such as opioids, antiemetics, phenothiazines 
and/or corticosteroids within $24 \mathrm{~h}$ before the study period.

The patients were allocated via a computergenerated list into three study groups. Patients in the Ondansetron group $(\mathrm{n}=29)$ received $4 \mathrm{mg}$ ondansetron, those in the Dexamethasone group $(\mathrm{n}=29)$ received 8mg Dexamethasone IV and the Propofol group $(\mathrm{n}=29)$ received $10 \mathrm{mg}$ Propofol IV bolus followed by $1 \mathrm{~m} / \mathrm{kg} / \mathrm{hr}$ IV infusion. The study drugs were prepared by a resident not participating in the study. Each patient received one of the previously prepared study solutions immediately after delivery of the infant and clamping of the umbilical cord. The attending anesthesiologist, the patient and the obstetrician were blinded to the study drug.

In the preadmission unit, baseline arterial blood pressure (BP) and heart rate were recorded.A suitable peripheral vein was cannulated for administration of study drugs and another for IV fluids. All patients were premedicated with IV Ranitidine $50 \mathrm{mg}$ and $10 \mathrm{~mL} / \mathrm{kg}$ of lactated Ringer's solution, before the surgery.

On arrival in the operation theatre, routine monitoring devices were placed including noninvasive arterial blood pressure, pulse rate, electrocardiogram, and pulse oximetry.

After positioning the patient in sitting position, spinal anesthesia was performed at the level of L3-L4 space through a midline approach using a 25-gauge Quincke spinal needle. Then $0.5 \%$ hyperbaric bupivacaine (8mg) with Fentanyl 25 mcg was injected intrathecally in all patients. After spinal anesthesia, patients was kept in supine position with left uterine displacement using a wedge under the right hip, and immediately the patient's systolic blood pressure and diastolic blood pressure were recorded, and thereafter every 2 min till the end of the surgery, along with heart rate and peripheral oxygen saturation. Supplemental oxygen was administered at the rate of $4 \mathrm{~L} / \mathrm{min}$ via nasal prongs until the delivery of the infant. The level of anesthesia was assessed by pinprick before surgical incision. The upper sensory dermatome level of the block (T4, nipple) was assessed and confirmed. Standard monitoring included electrocardiography, non-invasive $\mathrm{BP}$, and pulse oximetry recorded.

BP measurements were recorded every 2 minutes until the end of surgery. Systolic BP was maintained strictly at or above baseline values with aliquots of phenylephrine 50-100 mcg IV and IV fluids throughout the surgery. Hypotension was defined as a decrease in systolic BPbelow $80 \%$ of baseline despite the use of prophylactic vasopressors. Oxytocin 0.5 IU was administered IV after delivery of the infant, followed by a maintenance infusion of $40 \mathrm{mU} / \mathrm{min}$.

Patients were instructed, before the administration of anesthesia, to report the presence of nausea at any time during the surgery. Incidence of nausea was recorded when spontaneously reported. Retching and Vomiting was recorded as observed by blinded investigator.

In a pilot study the incidence of nausea \& vomiting after administration of $4 \mathrm{mg}$ Ondansetron around $60 \%$. The $\alpha$ value was set at 0.05 and power of the study $80 \%$. The expectedimprovement in nausea vomiting with new drug by $35 \%$ was set. Sample size in each group was calculated to be 30 . All the categorical data were compared using chi-square test and continuous data were compared using Anova using software package for social sciences (SPSS) version 23 .

\section{Results}

The groups were comparable with respect to maternal demographics [Table 1]. No statistically significant difference was observed between the two groups $(\mathrm{P}>0.05)$. The levelof analgesia was sufficient for caesarean delivery because none of the patients had a sensory level below T4 (nipple) as tested by pinprick bilaterally in the mid clavicular line. Total dose of Phenylephrine for the treatment of hypotension was similar between the groups, and no significant difference was found between the two groups.Patients in three groups were haemodynamically stable. The 
incidence of nausea, retching, and vomiting in the intraoperative, post-delivery period were as tabulated in Table 2 as follows Group O: Group D: Group P Nausea $58.6 \%$ versus $10.3 \%$ and
$20.6 \% \mathrm{P}=0.000$; Retching $44.8 \%$ versus $13.8 \%$, $24.1 \% \mathrm{P}=0.027$, Vomiting $41.3 \%, 13.7 \%$, versus $17.4 \% \mathrm{P}=0.028$. No clinically significant adverse events were observed among the groups.

Table 1: Demographic profile

\begin{tabular}{|l|c|c|c|c|}
\hline & Group O & Group D & Group P & P value \\
\hline Age (years) & $21.41 \pm 1.01$ & $21.21 \pm 0.82$ & $21.10 \pm 0.81$ & 0.404 \\
\hline Weight (kg) & $68.17 \pm 4.76$ & $68.62 \pm 4.32$ & $68.59 \pm 4.75$ & 0.919 \\
\hline ASA-PS (I/II) & $25 / 4$ & $24 / 5$ & $25 / 4$ & 0.914 \\
\hline Ute. Exterio. Time & $10.83 \pm 0.848$ & $10.86 \pm 0.875$ & $10.76 \pm 0.830$ & 0.895 \\
\hline I-D (min) & $7.28 \pm 1.192$ & $7.14 \pm 1.026$ & $7.34 \pm 1.111$ & 0.771 \\
\hline U-D Time (sec) & $80.00 \pm 11.339$ & $79.66 \pm 11.175$ & $76.90 \pm 12.278$ & 0.539 \\
\hline operation time & $40.34 \pm .721$ & $40.38 \pm .728$ & $40.52 \pm 1.122$ & 0.732 \\
\hline
\end{tabular}

$\mathrm{I}-\mathrm{D}=$ skin incision to delivery

$\mathrm{U}-\mathrm{D}$ time $=$ uterine incision to delivery

*Calculated by three-way ANOVA test

Table No. 2 Nausea, Vomiting and Retching

\begin{tabular}{|l|c|c|c|c|}
\hline & Group O & Group D & Group P & Pvalue \\
\hline Nausea (Y/N) & $17 / 12$ & $3 / 26$ & $6 / 23$ & 0.000 \\
\hline Retching(Y/N) & $13 / 16$ & $4 / 25$ & $7 / 22$ & 0.027 \\
\hline Vomiting (Y/N) & $12 / 17$ & $4 / 25$ & $5 / 24$ & 0.028 \\
\hline
\end{tabular}
Calculated by Chi-square test

\section{Discussion}

The overall incidence of IONV during regional anesthesia for Caesarean section is extremely variable, up to $80 \%$, depending on the anesthetic and surgicaltechnique and the preventive and therapeutic measures as studied by Albouleish EI (11). Various studies have shown reduction in the incidence of IONV duringCaesarean section by $22 \%-55 \%$ with the use of prophylactic antiemeticsBalki $\mathrm{M}$ et $\mathrm{al}^{(12)}$.

The cause of IONV in caesarean section under spinal anesthesia is multifactorial. Spinal anesthesia induced hypotension, vagal hyperactivity and the use of opioids both systemic and neuraxial all have been implicatedin the causation of IONV.The correlation of IONV during Caesarean section with the development of hypotension has been well established in the literature. Ngan Kee et al. ${ }^{(13)}$ found that when phenylephrine is titrated with the aim of maintaining maternal $\mathrm{BP}$ at $100 \%$ baseline in the predelivery period, the incidence of IONV is only $4 \%$, compared to $16 \%$ when the BP is maintained at $90 \%$, and $40 \%$, when it is at $80 \%$ of baseline. This implies the importance of strict BP control in preventing IONV.Datta et al. ${ }^{(20)}$ in their study concluded that in caesarean delivery, the emetic symptoms are influenced by maternal hypotension. Hypotension may cause brainstem hypoperfusion and thus trigger the vomiting centre to induce emesis by Ratraet al. ${ }^{(14)}$

In our study hypotension is avoided with prophylactic fluid preloading, left uterine displacement, use of low dose bupivacaine. Strict perioperative haemodynamic stability is maintained with the help ofaliquots of phenylephrine 50-100 mcg IV and IV fluids. Use of low dose neuraxial opioid (Fentanyl $25 \mathrm{mcg}$ ) helped minimise pain of uterine as well as intraabdominal manipulation thus limiting IONV further as has been suggested by Balki $\mathrm{M}$ et $\mathrm{al}^{(1)}$.

Liberal use of oxytocin have been implicated in development of IONV mainly due to the hypotension it produces Balki $\mathrm{M}$ et $\mathrm{al}^{(1)}$ So in our study oxytocin has been used very judiciously and slowly $(0.5 \mathrm{u}$ bolus followed by infusion of $40 \mathrm{mu} / \mathrm{min}$ ) to avoid hypotension and ionv.

The demographic profile in terms of age, weight, ASA PS, uterus exteriorization time, I-D interval (min), U-D time (sec) and operation time 
(min)between the two study groups were comparable, and no statistically significant difference was observed between the two groups $(\mathrm{P}>0.05)$. The incidence of nausea, retching, and vomiting in the intraoperative, post-delivery period were between our three group as follows Group O: Group D: Group P Nausea 58.6\% versus $10.3 \%$ and $20.6 \% \quad \mathrm{P}=0.000$; Retching $44.8 \%$ versus $13.8 \%, 24.1 \% \mathrm{P}=0.027$, Vomiting $41.3 \%$, $13.7 \%$, versus $17.4 \% \mathrm{P}=0.028$. No clinically significant adverse events were observed among the groups.

Nausea and vomiting can also occur after oxytocininduced hypotension. When administered in rapid boluses and large doses, oxytocin could be associated with significant hypotension and other hemodynamic consequences. Judicious use and administration of oxytocin in the form of infusion can overcome the problem of hypotension and its associated adverse effects.

In our study, we attempted to reduce IONV without any therapeutic intervention by adjusting the anesthetic technique. The measures such as strict control of BP, provision of dense anesthetic block, and the judicious use of uterotonic drugs can enhance our anesthetic technique considerably, especially in circumstances where exteriorization is preferred for uterine repair.

Numazaki et al. ${ }^{(16)}$ concluded that sub hypnotic dose of propofol $1.0 \mathrm{mg} / \mathrm{kg} / \mathrm{h}$ reduces the incidence of postdelivery nausea and vomiting in parturient undergoing caesarean delivery without excessive sedation, and is a more effective antiemetic than traditional antiemetics (droperidol and metoclopramide) for reducing the severity of nausea. ${ }^{(17)}$ The exact mechanism by which propofol inhibits intraoperative, postdelivery emesis is unknown, but there are possibilities that propofol possesses direct antiemetic properties according to Smith et al. ${ }^{(18)}$ and that reduced levels of serotonin in the area postrema are related to these antiemetic properties as concluded by Cechetto et al. ${ }^{(19)}$

Vomiting was observed by Gan et al. ${ }^{(21)}$ in the propofol group in $19 \%$, which is similar to the findings of our study (20\%), thereby suggesting propofol has a direct depressant effects on the chemoreceptor trigger zone, the vagal nuclei, and other centers implicated in nausea and vomiting.

Our results are almost similar with those of Fujii et al. ${ }^{[15]}$ where IV placebo (intralipid), propofol $0.5 \mathrm{mg} / \mathrm{kg}$, or propofol $0.5 \mathrm{mg} / \mathrm{kg}$ plus dexamethasone $8 \mathrm{mg}$ was used at the end of surgical procedure for prevention of PONV. The incidence of patients experiencing PONV during the first $24 \mathrm{~h}$ after anesthesia was $33 \%$ with propofol $(\mathrm{P}=0.003)$, 15\% with propofol plus dexamethasone $(\mathrm{P}=0.001)$ when compared to $65 \%$ with placebo. They concluded that propofol $0.5 \mathrm{mg} / \mathrm{kg}$ combined with dexamethasone $8 \mathrm{mg}$ was more effective than propofol alone for prevention of PONV in laparoscopic cholecystectomy during the first $24 \mathrm{~h}$ after anesthesia.

Dexamethasone lacks the sedative, dysphoric, and extrapyramidal signs associated with traditional antiemetics such as droperidol and metoclopramide. In a review by Bisgaard $^{(22)}$ dexamethasone was reported to be effective for the treatment of pain after laparoscopic cholecystectomy. Postoperative pain and supplementary opioid requirements were reduced by approximately $50 \%$ in patients receiving dexamethasone. Jaffarpour et al. ${ }^{(23)}$ concluded that prophylactic use of 8 mgdexamethasone is effective for reducing emetic symptoms and the analgesic requirements in women undergoing cesarean section under spinal anesthesia.

\section{Conclusion}

It can be concluded from this study that IVdexamethasone $8 \mathrm{mg}$ and IV Propofol $10 \mathrm{mg}$ bolus followed by infusion of propofol $1 \mathrm{mg} / \mathrm{kg} / \mathrm{h}$ is better than IV Ondansetron $4 \mathrm{mg}$ for reduction of the incidence of nausea, retching, and vomiting in the cesarean section under spinal anesthesia.IV Ondansetron $4 \mathrm{mg}$ is much less effective than IV Dexamethasone and IV propofol infusion. 


\section{References}

1. Balki M, Carvalho A. Intraoperative nausea and vomiting during cesarean section under regional anesthesia. Int $\mathbf{J}$ Obstet Anesth 2005;14:230-41.

2. Santos A, Datta S. Prophylactic use of droperidol for control of nausea and vomiting during spinal anesthesia for cesarean section. Anesth Analg 1984;63:85-7.

3. Borgeat A, Wilder-Smith $\mathrm{OH}$, Wilder-Smith $\mathrm{CH}$, Forni M, Suter PM. Propofol improves patient comfort during cisplatin chemotherapy. A pilot study. Oncology 1993;50:456-9.

4. Watcha MF, White PF. Postoperative nausea and vomiting. Its etiology, treatment, and prevention. Anesthesiology 1992;77:162-84.

5. Pan PH, Moore CH.Intraoperative antiemetic efficacy of prophylactic ondansetron versus droperidol for cesarean section patients under epidural anesthesia. AnesthAnalg1996;83:982-6.

6. Scher CS, Amar D, McDowall RH, Barst SM. Use of propofol for the prevention of chemotherapy-induced nausea and emesis in oncology patients. Can J Anaesth 1992;39:170-2.

7. Borgeat A, Wilder-Smith $\mathrm{OH}$, Saiah M, Rifat K. Subhypnotic doses of propofol possess direct antiemetic properties. AnesthAnalg1992;74:539-41.

8. Schulman SR, Rockett CB, Canada AT, Glass PS. Long-term propofol infusion for refractory postoperative nausea: A case report with quantitative propofol analysis. AnesthAnalg1995;80:636-7.

9. FujiiY, NumazakiM. Dose-range effects of propofol for reducing emetic symptoms during cesarean delivery. Obstet Gynecol 2002;99:75-9.

10. Zou Z, Jiang Y, Xiao M, Zhou R. The impact of prophylactic dexamethasone on nausea and vomiting after thyroidectomy: a systematic review and meta analysis. PloS One 2014; 357: e109582.

11. Abouleish E I, Rashid S, Haque S, Giezentanner A, Joynton P, Chuang A Z. Ondansetron versus placebo for the control of nausea and vomiting during caesarean section under spinal anaesthesia. Anaesthesia 1999; 54: 479-482.

12. Balki M, Kasodekar S, Dhumne S, Carvalho C. A. The Prophylactic Granisetron Does Not Prevent Postdelivery Nausea and Vomiting During Elective Cesarean Delivery Under Spinal Anesthesia. Anesth Analg2007;104:679 83.

13. Ngan Kee WD, Khaw KS, Ng FF. Comparison of phenylephrine infusion regimens for maintaining maternal blood pressure during spinal anesthesia for cesarean section. Br J Anaesth2004;92:469 $-74$.

14. Ratra CK, Badola RP, Bhargava KP. A study of factors concerned in emesis during spinal anaesthesia. $\mathrm{Br} \quad \mathrm{J}$ Anaesth1972;44:1208-11.

15. Fujii Y, Nakayama M. Prevention of PONV with a small dose of propofol alone and combined with dexamethasone in patients undergoing laparoscopic cholecystectomy. Clin Ther 2004;8: 1286-91.

16. Numazaki M, Fujii Y. Subhypnotic dose of propofol for the prevention of nausea and vomiting during spinal anaesthesia for caesarean section. Anaesth Intensive Care 2000;28:262-5.

17. Numazaki M, Fujii Y. Reduction of emetic symptoms during cesarean delivery with antiemetics: Propofol at subhypnotic dose versus traditional antiemetics. J Clin Anesth2003;15:423-7.

18. Smith I, White PF, Nathanson M, Gouldson R. Propofol. An update on its clinical use. Anesthesiology 1994;81:1005-43. 
19. Cechetto DF, Diab T, Gibson CJ, Gelb AW. The effects of propofol in the area postrema of rats. Anesth Analg 2001;92:934-42.

20. Datta S, Alper MH, Ostheimer GW, Weiss JB. Method of ephedrine administration and nausea and hypotension during spinal anesthesia for cesarean section. Anesthesiology1982;56:68-70.

21. Gan TJ, Ginsberg B, Grant AP, Glass PS. Double-blind, randomized comparison of ondansetron and intraoperative propofol to prevent postoperative nausea and vomiting. Anesthesiology 1996;85: 1036-42.

22. Bisgaard T, Klarskov B, Kehlet H, Rosenberg J. Preoperative dexamethasone improves surgical outcome after laparoscopic cholecystectomy: A randomized double-blind placebocontrolled trial. Ann Surg 2003; 238:651-60.

23. Jaffarpour M, Khani A, Dyrekvandmoghadam A, Khajavikhan J, Saadipour KH. The effect of dexamethasone on nausea, vomiting and pain in parturients undergoing caesarean delivery. J Clin Diagn Res 2008;3:854-8.

24. Ramsay MA, Savege TM, Simpson BR, Goodwin R. Controlled sedation with alphaxalone-alphadolone. $\mathrm{Br}$ Med J 1974;2:656-9.

25. Fischer SP. Pre-operative evaluation. In: Lars IE, Lee AF, Jeanie PW, WilliamL Y, Miller RD, editors. Miller's Anaesthesia. 7th ed. Philadelphia: Elsevier Churchill Livingstone; 2010. p. 1001-66.

26. Hvarfner A, Hammas B, ThörnSE, Wattwil M. The influence of propofol on vomiting induced by apomorphine. Anesth Analg1995;80:967-9. 